\title{
Development of a Multiplex RT- PCR Assay for Simultaneous Detection of Four Potential Zoonotic Swine Enteric RNA Viruses
}

\section{Yue Wang ( $\nabla$ wangyue@caas.cn )}

Harbin Veterinary Research Institute https://orcid.org/0000-0003-1575-3569

\section{Gebremeskel Mamu Werid}

HVRI: Chinese Academy of Agricultural Sciences Harbin Veterinary Research Institute

Yassein M. Ibrahim

Chinese Academy of Agricultural Sciences Harbin Veterinary Research Institute

He Zhang

HVRI: Chinese Academy of Agricultural Sciences Harbin Veterinary Research Institute

Yu Pan

HVRI: Chinese Academy of Agricultural Sciences Harbin Veterinary Research Institute

\section{Lin Zhang}

HVRI: Chinese Academy of Agricultural Sciences Harbin Veterinary Research Institute

\section{Yunfei Xu}

HVRI: Chinese Academy of Agricultural Sciences Harbin Veterinary Research Institute

\section{Wenli Zhang}

HVRI: Chinese Academy of Agricultural Sciences Harbin Veterinary Research Institute

\section{Wei Wang}

HVRI: Chinese Academy of Agricultural Sciences Harbin Veterinary Research Institute Hongyan Chen

HVRI: Chinese Academy of Agricultural Sciences Harbin Veterinary Research Institute

\section{Research Article}

Keywords: mRT-PCR, Swine potential zoonotic viruses, Sav, EMCV, RVA and AstV

Posted Date: February 1st, 2022

DOI: https://doi.org/10.21203/rs.3.rs-1293592/v1

License: (c) (1) This work is licensed under a Creative Commons Attribution 4.0 International License. Read Full License 


\section{Abstract}

Swine enteric viruses like porcine Sapovirus (SaV), porcine encephalomyocarditis virus (EMCV), porcine rotavirus $A(R V A)$ and porcine astroviruses (AstV) are potentially zoonotic viruses or suspected of potential zoonosis. These viruses have been detected in pigs with or without clinical signs and often occur as coinfections. Despite the potential public health risks, no assay for detecting them all at once has been developed. Hence, in this study, a multiplex RT-PCR (mRT-PCR) assay was developed for the simultaneous detection of SaV, EMCV, RVA and AstV from swine fecal samples. The PCR parameters were optimized using specific primers for each target virus. The assay's sensitivity, specificity, reproducibility, and application to field samples have been evaluated. Using a pool of plasmids containing the respective viral target fragments as a template, the developed mRT-PCR successfully detected $2.5 \times 10^{3}$ copies of each target virus. The assay's specificity was tested using six other enteric viruses as a template and did not show any cross-reactivity. A total of 280 field samples were tested with the mRT-PCR assay. Positive rates for SaV, EMCV, RVA, and AstV were found to be $24.6 \%(69 / 280), 5 \%$ (14/280), 4.3\% (12/280), and 17.5\% (49/280), respectively. Compared to performing separate assays for each virus, this mRT-PCR assay is a simple, rapid, and cost-effective method for detecting mixed or single infections of SaV, EMCV, RVA, and AstV.

\section{Introduction}

Swine enteric viruses cause a major economic loss in the swine industry [1-5]. So far, more than sixteen porcine enteric viruses have been identified [6-9]. From these swine enteric viruses, due to the asymptomatic nature of infections, unless there is a confounding factor or a mixed infection of another pathogenic virus, infections from porcine Sapovirus (SaV), encephalomyocarditis virus (EMCV), Porcine rotavirus $A(R V A)$ and porcine astrovirus (AstV) might not be noticed [10-13]. Though the economic impact of SaV, EMCV, RVA and AstV viruses on the swine industry might not be significant enough to attract the attention of pig producers, their potential to become zoonotic diseases warrants proper attention [12]. More importantly, even asymptomatic pigs can shed the virus into the environment or can directly transmit it to people at risk [45]. Likewise, SaV, EMCV, RVA, and AstV were found genetically closely related to human viruses and hence have a zoonotic potential and/or are suspected of zoonosis $[5,11,12,14-18]$.

To develop vaccines against the prevalent viral strains, early and accurate virus detection is needed and hence, early virus detection is an integral part of disease control and prevention programs [19]. However, coinfection, which is common in swine enteric viruses, complicates early and accurate virus detection. In the presence of coinfection, it's often difficult to know the underlining cause of disease [20,21]. This is because, in the presence of coinfection, viruses that don't usually cause apparent clinical signs during a single infection could contribute to the severity of an existing infection, further complicating disease diagnosis [11, 22]. Moreover, compared to other swine enteric viruses, these potential zoonotic enteric viruses, due to their high coinfection rate, higher virus shedding, fecal-oral transmission, asymptomatic 
nature, and potential to transmit to humans; demands special attention for early detection and accurate identification.

Virus isolation, electron microscopy, serological tests, and nucleic acid detection methods are the most commonly used methods for detecting viruses $[21,23,24]$. Recently nucleic acid-based and serological detection methods are being used widely for diagnosing enteric swine viral infections [23-25]. Nucleic acid-based detection methods are preferred over serological methods for determining current infection status [26]. The existing nucleic acid-based diagnostic assays for detecting potential zoonotic swine enteric viruses depend on a single PCR. These single PCR-based detection methods consume more time and resources to detect each virus at a one-time point. Whereas, using multiplex PCR assays, nucleic acid detection methods have another added advantage for the simultaneous detection of viruses [24, 25]. Multiplex reverse transcriptase PCR (mRT-PCR) based virus diagnostic assays provide both the affordability and accuracy of virus detection, enabling faster and wider field-based applications $[23,26]$. In this study, in an attempt to solve challenges associated with detecting potential zoonotic swine enteric viruses, a multiplex PCR assay that could simultaneously detect SaV, EMCV, RVA and AstV from porcine fecal samples has been developed.

\section{Materials And Methods}

\section{Nucleic acid extraction and reverse transcription}

Pooled swine fecal samples were collected, and $10 \%(\mathrm{w} / \mathrm{v})$ stool suspensions were mixed with PBS (phosphate-buffered saline), centrifuged at $400 \mathrm{~g}$ for 20 minutes at $4^{\circ} \mathrm{C}$, and supernatants were collected. Total RNA was extracted from fecal supernatants using the Tiangen virus RNA extraction kit (Tiangen Biotech, Beijing) according to manufacture instructions.

Complementary DNA (cDNA) was synthesized in a $20 \mu \mathrm{L}$ reverse transcription (RT) reaction mixture containing of $2 \mu \mathrm{L}$ of Golden MLV buffer, $1 \mu \mathrm{L}$ Golden MLV enzyme, $1 \mu \mathrm{L}$ Random hexamer primers and $1 \mu \mathrm{L}$ dNTP, $0.5 \mu \mathrm{L}$ Rnase inhibitor and $1 \mu \mathrm{g}$ of total RNA and RNase free double distilled water $\left(\mathrm{ddH}_{2} \mathrm{O}\right)$ and then incubated at $37^{\circ} \mathrm{C}$ for 15 minutes and at $85^{\circ} \mathrm{C}$ for 5 seconds (TakaRa, Dalian, China).

\section{Primer design and Construction of SaV, EMCV, RVA and ASTV plasmids}

The primers (Table 1) were designed with primer3[27] and used to amplify the fragments of SaV, EMCV, RVA, and AstV from swine fecal samples. Each amplicon was purified and cloned into the pMD18-T vector (TaKaRa, Dalian, China). The plasmids were transformed into competent Escherichia coli DH5a cells. The plasmids were extracted using a mini plasmid extraction kit (Tiangen, Beijing, China) from bacterial solution cultured at $37^{\circ} \mathrm{C}$ for $14-16 \mathrm{~h}$ and quantified by a NanoDrop spectrophotometer (Thermo Fisher, USA). The plasmid constructs were confirmed by PCR and sequencing (CometBio, Jilin, China). The plasmids were used as templates for mRT-PCR optimization. 
Table 1

List of primers used for detection of SaV, EMCV, RVA and AstV by the mRT-PCR.

\begin{tabular}{|c|c|c|c|c|c|}
\hline Primer & Sequence $\left(5^{\prime} \rightarrow 3^{\prime}\right)$ & $\begin{array}{l}\text { Target } \\
\text { gene }\end{array}$ & $\begin{array}{l}\text { Accession } \\
\text { no. }\end{array}$ & $\begin{array}{l}\text { Target region } \\
\text { (nt) }\end{array}$ & $\begin{array}{l}\text { Amplicon size } \\
\text { (bp) }\end{array}$ \\
\hline SaV-F & agccagaagtgttcgtgatgg & \multirow[t]{2}{*}{ ORF1 } & \multirow[t]{2}{*}{ MK965898.1 } & \multirow[t]{2}{*}{$5124-5429$} & \multirow[t]{2}{*}{306} \\
\hline SaV-R & ggacargtgragygtgtargg & & & & \\
\hline $\begin{array}{l}\text { EMCV- } \\
\mathrm{F}\end{array}$ & ccgtcaagtcttccaaccag & \multirow[t]{2}{*}{$3 D$} & \multirow[t]{2}{*}{ МH191297.1 } & \multirow[t]{2}{*}{$6288-6725$} & \multirow[t]{2}{*}{438} \\
\hline $\begin{array}{l}\text { EMCV- } \\
\mathrm{R}\end{array}$ & gcggcttgaaccttctctatc & & & & \\
\hline RVA-F & gcaaacgaagtcttcgacatgg & \multirow[t]{2}{*}{ VP6 } & \multirow[t]{2}{*}{ МH308723.1 } & \multirow[t]{2}{*}{ 8- 574} & \multirow[t]{2}{*}{570} \\
\hline RVA-R & ggcgttaatccacatagtyccca & & & & \\
\hline $\begin{array}{l}\text { AstV - } \\
\mathrm{F}\end{array}$ & ttgtggagcttgactggacc & \multirow[t]{2}{*}{ ORF1ab } & \multirow[t]{2}{*}{ MK613068.1 } & \multirow[t]{2}{*}{$3341-4042$} & \multirow[t]{2}{*}{702} \\
\hline AstV-R & ctgtgagtcttgcaggcaga & & & & \\
\hline
\end{tabular}

\section{Single RT-PCR and $\mathrm{mRT}$-PCR reaction optimization}

Prior to performing mRT-PCR, the designed primers were used to perform single RT-PCR (sRT-PCR) for SaV, EMCV, RVA, and AstV. A $40 \mu \mathrm{L}$ PCR reaction was prepared using $5 \mu \mathrm{L}$ of cDNA, 5\% DMSO, rTaq enzyme (0.5-1 unit), $0.25 \mu \mathrm{M}$ of each primer, $1.5 \mathrm{mM} \mathrm{MgCl}_{2}, 0.2 \mathrm{mM}$ dNTP, $4 \mathrm{X}$ rTaq buffer and autoclaved $\mathrm{ddH}_{2} \mathrm{O}$ was added to make $40 \mu \mathrm{L}$ volume. In the negative control reaction, ddH2O was used as a template. In a Bio-Rad PCR Thermo Cycler (Bio-Rad, CA, USA), the prepared reaction was amplified as follows: one cycle at $94^{\circ} \mathrm{C}$ for 5 minutes; 35 cycles of denaturation at $98^{\circ} \mathrm{C}$ for 10 seconds; gradient annealing $\left(48^{\circ} \mathrm{C}\right.$ to $58^{\circ} \mathrm{C}$ ) for 30 seconds; $72^{\circ} \mathrm{C}$ for 45 seconds extension; and a final extension step of 10 minutes at $72^{\circ} \mathrm{C}$. Gel electrophoresis with a 1.5 percent agarose gel in $1 \mathrm{TAE}$ buffer was used to examine PCR results.

The mRT-PCR reactions were optimized by varying a single parameter while keeping other parameters constant. To explore optimum conditions, annealing temperature (from 48 to $58 \circ \mathrm{C}$ ), number of cycles $(25$ to 40 ), primer concentration (from $0.05 \mu \mathrm{M}$ to $0.4 \mu \mathrm{M}$ ), $\mathrm{MgCl} 2$ (from 1.0 to $4.0 \mathrm{mM}$ ), dNTP (from 0.3$0.9 \mathrm{mM}$ ), and TakaRa rTaq DNA Polymerase (from 2 to $6 \mathrm{U}$ ) were tested in a $40 \mu \mathrm{L}$ PCR reaction volume. The PCR products were visualized using gel electrophoresis on a 1.5 percent agarose gel in 1 TAE buffer. Following mRT-PCR condition optimization, the amplicons were sequenced for confirmation (CometBio, Jilin, China).

\section{Assay sensitivity, specificity, and reproducibility}

The sensitivity of sRT-PCR and mRT-PCR was compared using a 10-fold serially diluted standard plasmids of known DNA copy number. The DNA copy number of each standard plasmid was calculated using the formula described in [24]. To serve as a template for the SRT-PCR and mRT-PCR, $10^{6} \mathrm{copies} / \mu \mathrm{L}$ 
of each cloned virus fragment were mixed into a single tube and diluted 10 -fold serially at a concentration gradient of $10^{0}$ to $10^{6}$ copies $/ \mu \mathrm{L}$.

Specificity of the developed mRT-PCR was tested by using CDNA porcine epidemic diarrhea virus (PEDV), Seneca Valley virus (SVV), transmissible gastroenteritis virus (TGEV), porcine respiratory and reproductive syndrome virus (PRRSV), porcine delta Coronavirus (PDCoV), porcine sSapelo virus (PSV)es and porcine enterovirus (PEV) mixed with the cDNA of each of the viruses included in the mRT-PCR as templates. The amplicons were purified and sequenced to confirm the specificity of the assay.

To evaluate the intra-assay reproducibility of the developed assay, mRT-PCR reactions were performed in triplicate on each optimized parameter. Furthermore, inter-assay reproducibility was tested by running four different PCR reactions under optimized conditions with freshly prepared templates.

\section{Detecting target viruses from field samples using mRT-PCR}

The developed mRT-PCR assay was used to test a pool of 280 porcine fecal field samples for SaV, EMCV, RVA, and AstV, and 130 of these samples were also tested using single PCR Primers for each virus.

\section{Phylogenetic analysis of the detected viruses}

Some of the porcine fecal field samples which were mRT-PCR positive for SaV, EMCV, RVA and AstV were reamplified using SRT-PCR. The amplified and purified PCR products were sequenced. MEGA-X program was used to align the nucleotide sequences. The phylogenetic trees were constructed with MEGA-X software using the neighbor-joining method [28], Kimura distances, and a bootstrap sampling technique with 1000 replicates [29].

\section{Results}

\section{Optimized conditions of the mRT-PCR}

Before $m$ RT-PCR reaction optimization, sRT-PCR standardization and optimum annealing temperature determination were done using gradient PCR for each virus at a temperature of 48 to $58^{\circ} \mathrm{C}$. Primers of SaV, EMCV, RVA and AstV produced an amplicon size of $305 \mathrm{bp}, 438 \mathrm{bp}, 570 \mathrm{bp}$ and $702 \mathrm{bp}$, respectively. The annealing temperature was optimized at $50-52{ }^{\circ} \mathrm{C}$. After optimizing the annealing temperature, each PCR reaction condition was optimized one at a time by keeping other components constant. After repetitive experiments, an optimum concentration of $\mathrm{dNTP}, \mathrm{MgCl}_{2}$ and Taq polymerase was determined at $0.6 \mathrm{mM}, 0.35 \mathrm{mM}$ and 6 units, respectively. Primer concentration were optimized at $0.15,0.113,0.15$ and $0.1 \mu \mathrm{M}$ for SaV, EMCV, RVA and AstV respectively. All reactions were performed at $40 \mu \mathrm{l}$ reaction volume and 35 cycles. Each of the amplicons was visualized by electrophoresing $10 \mu \mathrm{L}$ aliquots through $1.5 \%$ agarose gels in 1X TAE (40 mM Tris-acetate [pH 8.0], 1 mM EDTA). all four viruses were amplified successfully using the optimized mRT-PCR conditions (Fig. 1A). 
Figure 1 mRT-PCR optimization and assay specificity. M:2000 bp marker, 1: SaV, 2: EMCV, 3: RVA and 4: AstV, P: standard plasmid template mix containing SaV, EMCV, RVA and AstV fragments. (A) Optimization of mRT-PCR using plasmids containing SaV, EMCV, RVA and AstV fragments. (B) Assay specificity. N: negative control, 1: SaV, 2: EMCV, 3: RVA, 4: AstV and 5-10: cDNA of PEDV, SVV, TGEV, PRRSV, PDCoV and PSV respectively

\section{Assay sensitivity}

The sensitivity of SRT-PCR and mRT-PCR was tested using ten-fold serial dilutions of the SaV, EMCV, RVA and AstV plasmid constructs. It was found that the developed mRT-PCR assay could simultaneously detect up to $2.5 \times 10^{3}$ copies of each template, while single PCR could detect $2.5 \times 10^{1}, 2.5 \times 10^{3}, 2.5 \times 10^{2}$, and $2.5 \times 10^{2}$ copies of SaV, EMCV, RVA and AstV, respectively (Fig. 2).

\section{Assay specificity}

The specificity of each primer pairs was determined using sRT-PCR and mRT-PCR (Fig. 1B). Both sRT-PCR and $m R T$-PCR were found specific for the target viral agent because no amplicons were produced with other viral agents, including PEDV, SVV, TGEV, PRRSV, PDCoV, PSV (Fig. 1B, lanes 5-10). All positive amplicons were sequenced to check the presence of potential false-positive results. Basic Local Alignment Search Tool (BLAST; http://www.ncbi.nlm.nih.gov) was used to search homologous sequences and analyses of the sequences obtained corresponding to $305 \mathrm{bp}$ for SaV, $438 \mathrm{bp}$ for EMCV, $570 \mathrm{bp}$ for RVA, and $702 \mathrm{bp}$ AstV, respectively, were found to be identical to each virus. This result showed that the developed mRT-PCR assay is specific.

\section{Assay reproducibility}

Four different mRT-PCR reactions were performed at different times to assess inter-assay reproducibility using the same reaction conditions (Fig. 3). A freshly extracted plasmid was used as a template for each PCR reaction. Each of the four mRT-PCR reactions showed a similar result, indicating the reproducibility of the assay. Besides inter-assay reproducibility, intra-assay reproducibility was checked by carrying out triplicate mRT-PCR reactions (data not shown). The developed mRT-PCR assay's intra-assay and interassay reproducibility tests showed that it could be used to detect potentially zoonotic swine enteric viruses.

\section{Detection of field samples}

A total of 280 porcine fecal samples were tested for SaV, EMCV, RVA and AstV using the developed mRTPCR assay. Among the 280 samples, the positive rate of single infection for SaV was $24.6 \%(69 / 280)$ and the coinfection rate of SaV and EMCV, SaV and RVA, SaV and AstV was 2.9\% (8/280), 2.1\% (6/280) and $6.4 \%(18 / 280)$ respectively. The positive rate of single infection for EMCV was $5 \%(14 / 280)$. The coinfection rate of EMCV and RVA, and EMCV and AstV was 0.35\% (1/280) and 2.1\% (6/280), 
respectively. The single infection positive rate for RVA was $4.3 \%(12 / 280)$ and the coinfection rate of RVA and $A s t V$ was $2.9 \%$ (8/280). Moreover, a single infection positive rate of AstV was 17.5\% (49/280).

For checking the reliability of the mRT-PCR assay, in addition to testing by mRT-PCR assay, 130 samples were selected and further tested using sRT-PCR for SaV, EMCV, RVA and AstV. Except for SaV (Table 2), samples positive for each virus using a single PCR test also showed similar positive results when tested by mRT-PCR. Some of the mRT-PCR positive samples were also checked by sequencing. The concordance of sequence results was then checked by subjecting to NCBI nucleotide blast and found no false-positive results.

Table 2

Detection of four viruses in 130 field samples by sRT-PCR and mRT-PCR.

\begin{tabular}{|c|c|c|c|c|}
\hline \multirow[t]{2}{*}{ Assay } & \multicolumn{4}{|c|}{ Number of positive samples } \\
\hline & SaV & EMCV & RVA & AstV \\
\hline sRT-PCR & 29 & 8 & 2 & 13 \\
\hline mRT-PCR & $27 *$ & 8 & 2 & 13 \\
\hline \multicolumn{5}{|c|}{$\begin{array}{l}\text { * The results were similar except for two samples that were positive for SaV by sRT-PCR but negative } \\
\text { by mRT-PCR. }\end{array}$} \\
\hline
\end{tabular}

\section{Phylogenetic analysis}

For each of the four viruses, phylogenetic trees were constructed using the neighbor-joining method based on the amplified fragments of the target region of some selected sequences from GenBank and nucleotide sequences obtained in this study. When constructing the phylogenetic trees, geographic location, host type, and virus genotype were all considered. The viral variants identified in this study are indicated by red circles (Fig.4), and all trees are drawn to scale, with branch lengths equal to the evolutionary distances used to infer the phylogenetic tree. The evolutionary distances were calculated using the Maximum Composite Likelihood method[30] and are expressed in base substitutions per site.

Within the Caliciviridae family, based on their complete VP1 nucleotide sequences, sapoviruses could be classified into 15 genogroups, eight of which have been detected in swine (GIII, GV-GXI) [31, 32] but only the GI, GII, GIV, and GV genogroups are known to infect humans [31, 33, 34]. To investigate the genetic diversity of several of the sequences identified in this study, we performed a phylogenetic analysis using 32 reference nucleotide sequences from GenBank with and 224 positions from Sapovirus ORF1 region. The SaV strains identified in this study named (Sapo 1, Sapo 2, Sapo3 and Sapo 5) clustered within the GIII genogroup and were found to be closely related to other GIII SaV strains detected in China (MW285642) and Mexico (MH490911). Whereas Sapo 4, which is also classified as a GIII genogroup member, formed a separate clade (Fig. 4A). 
EMCV is a Picornaviridae virus that infects many animals, including pigs, mice, primates, and humans [35]. The EMCV strains isolated from various animals, for example, pigs and rats, demonstrated a high degree of homology [36]. Thus, to investigate the genetic variability of the detected EMCV variants, we constructed a phylogenetic tree for EMCV using 22 reference nucleotide sequences from GenBank and 3 EMCV detected in this study named (EMCV1, EMCV2, and EMCV3) with 211 positions per sequence. According to the partial sequence of the 3D region, EMCV 3 detected in this study clustered with other EMCV strains from Japan (LC508268), whereas EMCV 1 and EMCV 2 clustered separately and more closely related to strains from China (Fig. 4B).

The RVA phylogenetic tree was constructed using a total of 33 RVA nucleotide sequences previously reported from various geographic locations and hosts, as well as strains detected in this study. The RVA variants identified in this study clustered into two distinct clades, with R1 and R2 belonging to one clade and R3 to another clade. However, all RVA variants identified in this study are more closely related to RVA previously described from China (MT874988, FJ617209 and KT82077), implying that they may have originated from the common ancestor. R1 and R2 clustered with MT874988 and FJ617209, previously described from China, whereas R3 clustered with KT820771, another Chinese RVA strain (Fig. 4C).

For AstV, phylogenetic analysis was performed using 25 nucleotides published sequences with 379 positions within the ORF1ab region, and seven AstV variants identified in this study named (Ast 1-7). All AstV variants detected during this study clustered under AstV4. Furthermore, Ast 1, 2, 3, 5 and Ast 7 clustered closely with AstV from China (MK460231) and Kenya (MT451918), whereas Ast 4 and Ast 6 clustered independently and close to strain from the USA (JX556692) (Fig. 4D).

\section{Discussion}

Despite the presence of a plethora of different types of diagnostic assays, nucleic acid-based assays offer an added advantage of high specificity and sensitivity with the possibility of a lower detection limit [37]. Recently, mRT-PCR is being used as one of the most important diagnostic methods for rapidly and simultaneously detecting viral pathogens. And hence, different mRT-PCR assays for simultaneously detecting nine [38], six [25, 39], five [40], four [23, 24, 26, 41], three [42] and two [43, 44] swine enteric viruses have been developed. Due to the asymptomatic nature of SaV, EMCV, RVA, and AstV infections, these viruses have received insufficient attention, and no single diagnostic assay capable of simultaneously detecting these viruses from porcine fecal samples has been developed.

A mRT-PCR assay capable of simultaneously detecting SaV, EMCV, RVA, and AstV RNA from porcine fecal samples was developed in this study. Our assay and other previously developed assays [23, 26]for other viruses suggest that sRT-PCR may be more specific than mRT-PCR, but the improvement in turnaround time and cost-effectiveness would compensate for this minor reduction in sensitivity. Yet, compared to SRT-PCR, mRT-PCR is more economical and rapid. The sensitivity of the developed mRT-PCR assay using plasmids containing the specific viral target fragments was $2.5 \times 10^{3}$ copies for each template. Similarly, Zhao, et al. [23] reported a similar mRT-PCR assay sensitivity of $2.17 \times 10^{3}, 2.1 \times 10^{3}, 1.74 \times 10^{4}$ and 1.26 
$\times 10^{4}$ for porcine epidemic diarrhea virus, transmissible gastroenteritis virus, RVA, and porcine circovirus 2 , respectively. Thus, the currently developed mRT-PCR assay has similar sensitivity with $\mathrm{Hu}$, et al. [41] and Liu, et al. [26], a higher sensitivity compared to Day, et al. [45] and Cagirgan and Yazici [46], and lower sensitivity compared to Liu, et al. [40]. Further, 130 fecal samples were tested for checking the difference in sensitivity of sRT-PCR and mRT-PCR assays. Test results of mRT-PCR showed an overall concordance rate of $98.5 \%$ (128/130) (Table 2) to the test results of sRT-PCR. Besides sensitivity, test results of specificity and reproducibility of this assay indicate that similar to the SRT-PCR, the developed mRT-PCR could be employed to detect SaV, EMCV, RVA, and AstV from porcine fecal samples. Similarly, previous reports $[25,38]$ and others suggested that mRT-PCR could be a highly sensitive and specific assay that could be used for rapid detection of enteric swine viruses.

To further confirm the validity of the developed mRT-PCR assay, 280 porcine fecal samples were tested and the positive rates of SaV, EMCV, RVA and AstV was found to be $24.6 \%(69 / 280), 5 \%$ (14/280), $4.3 \%$ (12/280), and $17.5 \%$ (49/280) respectively. This shows that, compared to the other two viruses, SaV has the highest positive rate and RVA the lowest positive rate. Similarly, SaV, EMCV, RVA, and AstV have been detected in diarrheic and non-diarrheic swine feces $[5,11-13,15]$, highlighting the importance of detecting these viruses in swine farms. In swine, coinfection of enteric viruses is common. In this study, a coinfection rate of $6.4 \%(18 / 280), 2.86 \%(8 / 280), 2.86 \%$ (8/280), $2.1 \%(6 / 280), 2.1 \%(6 / 280)$ and $0.35 \%$ $(1 / 280)$ for SaV \& AstV, SaV \& EMCV, RVA\& AstV, EMCV\& AstV, SaV \& RVA, and for EMCV \& RVA respectively has also been observed. Similar to the current study, coinfections of pigs with different enteric viruses have been reported from China [25, 47], the United States[48] and Belgium [49].

A phylogenetic analysis was also made to explore further the epidemiologic characteristics of the detected viruses. The phylogenetic analysis revealed that the SaV detected in this study belongs to the GIII genogroup. Similar to this study, previous research $[50,51]$ indicated that from the eight SaV genogroups detected in swine [31, 32], the GIII genogroup is the most prevalent in China. Phylogenetic analysis of the partial sequence of the 3D region of EMCV, similar to previous studies from China [52, 53], revealed that the EMCV variants detected in this study clustered into two groups. Yuan, et al. [53] assigned the EMCV-30 strain (DQ288856) from the USA and the Korean strains K3 (EU780148) and K11 (EU780149) to the EMCV group one lineage while strains PV2 (X87335) and D variant (M37588) to group two lineage. Based on Yuan, et al. [53], three of the EMCV strains identified in this study may belong to group one lineage, regardless of their clustering pattern. Based on the VP7 gene sequence, Group A rotaviruses are classified into $36 \mathrm{G}$ genotypes, of which 12 G-genotypes (G1-G6, G8-G12, and G26) have been identified in porcine $[18,54]$. All three RVA variants detected in this study are closely grouped with strains NJ2012 (MT874988.1) and TA-3-1 (KT820771.1), both of which are G9 genotypes, implying that the RVA variants detected in this study could be G9 genotype. According to phylogenetic analysis, the AstV variants detected in this study belong to AstV4. Similarly, Previous reports from the United States [55], Thailand [56] and Slovakia[8] indicated that AstV4 is the most prevalent type of AstV. In Contrast, a higher prevalence of AstV2 from China [57] and AstV5 from China's Hunan province [58] have also been observed, highlighting the importance of further AstV epidemiology study. These findings lend credence 
to the notion that coinfection of these viruses is common in swine. Through recombination and mutations, the coinfection of viruses accelerates the evolution of coinfected viruses [59, 60], allowing more virulent virus strains to emerge. As a result, the developed mRT-PCR assay could play a critical role in controlling and preventing SaV, EMCV, RVA, and AstV through early and accurate detection.

\section{Conclusion}

The assay's sensitivity, specificity, and repeatability demonstrated that SaV, EMCV, RVA, and AstV could be detected simultaneously in swine feces. Potential zoonotic swine enteric viruses such as SaV, EMCV, RVA and AstV are prevalent in China. These viruses frequently exist in pigs as a coinfection, necessitating the employment of specialized diagnostic techniques for quick diagnosis. The current mRT-PCR may help to reduce the cost and time associated with sample processing and testing during large-scale field sample screening for these viruses. Thus, the assay may help control and prevent potential zoonotic swine enteric viruses such as SaV, EMCV, RVA, and AstV by detecting them early and accurately.

\section{Declarations}

\section{Compliance with Ethical Standards}

This article does not contain any studies with human participants or animals performed by any of the authors.

\section{Conflict of interest}

The authors declare that they have no conflicts of interest with the contents of this manuscript.

\section{Funding and additional information}

This research was supported by Grants from National Key R\&D Program of China (2021YFF0703100) and Key Research \& Development Program of Heilongjiang province (grant number GZ20210010).

\section{References}

1. Zhou P, Fan H, Lan T, Yang X-L, Shi W-F, Zhang W, Zhu Y, Zhang Y-W, Xie Q-M, Mani S (2018) Fatal swine acute diarrhoea syndrome caused by an HKU2-related coronavirus of bat origin. Nature 556:255-258. .https://doi.org/10.1038/s41586-018-0010-9

2. Ge F-F, Yang D-Q, Ju H-B, Wang J, Liu J, Liu P-H, Zhou J-P (2013) Epidemiological survey of porcine epidemic diarrhea virus in swine farms in Shanghai, China. Arch Virol 158:2227-2231. .https://doi.org/10.1007/s00705-013-1722-7

3. Mandelik R, Sarvas M, Jackova A, Salamunova S, Novotny J, Vilcek S (2018) First outbreak with chimeric swine enteric coronavirus (SeCoV) on pig farms in Slovakia-lessons to learn. Acta veterinaria Hungarica 66:488-492. .https://doi.org/10.1556/004.2018.043 
4. Bank-Wolf BR, König M, Thiel H-J (2010) Zoonotic aspects of infections with noroviruses and sapoviruses. Vet Microbiol 140:204-212. https://doi.org/10.1016/j.vetmic.2009.08.021

5. Midgley SE, Bányai K, Buesa J, Halaihel N, Hjulsager CK, Jakab F, Kaplon J, Larsen LE, Monini M, Poljšak-Prijatelj M (2012) Diversity and zoonotic potential of rotaviruses in swine and cattle across Europe. Vet Microbiol 156:238-245. .https://doi.org/10.1016/j.vetmic.2011.10.027

6. Saif LJ (1999) Comparative pathogenesis of enteric viral infections of swine. Mechanisms in the Pathogenesis of Enteric Diseases 2 473:47-59. https://doi.org/10.1007/978-1-4615-4143-1_4

7. Zhou W, Ullman K, Chowdry V, Reining M, Benyeda Z, Baule C, Juremalm M, Wallgren P, Schwarz L, Zhou $E$ (2016) Molecular investigations on the prevalence and viral load of enteric viruses in pigs from five European countries. Vet Microbiol 182:75-81.

.https://doi.org/10.1016/j.vetmic.2015.10.019

8. Salamunova S, Jackova A, Mandelik R, Novotny J, Vlasakova M, Vilcek S (2018) Molecular detection of enteric viruses and the genetic characterization of porcine astroviruses and sapoviruses in domestic pigs from Slovakian farms. BMC Vet Res 14:1-9. .https://doi.org/10.1186/s12917-018$1640-8$

9. Pan Y, Tian X, Qin P, Wang B, Zhao P, Yang Y-L, Wang L, Wang D, Song Y, Zhang X (2017) Discovery of a novel swine enteric alphacoronavirus (SeACoV) in southern China. Vet Microbiol 211:15-21. .https://doi.org/10.1016/j.vetmic.2017.09.020

10. Theuns S, Conceicao-Neto N, Zeller M, Heylen E, Roukaerts ID, Desmarets LM, Van Ranst M, Nauwynck HJ, Matthijnssens J (2016) Characterization of a genetically heterogeneous porcine rotavirus $\mathrm{C}$, and other viruses present in the fecal virome of a non-diarrheic Belgian piglet. Infect Genet Evol 43:135-145. .https://doi.org/10.1016/j.meegid.2016.05.018

11. Chao DY, Wei JY, Chang WF, Wang J, Wang LC (2012) Detection of multiple genotypes of calicivirus infection in asymptomatic swine in Taiwan. Zoonoses Public Health 59:434-444. https://doi.org/10.1111/j.1863-2378.2012.01483.x

12. Machnowska P, Ellerbroek L, Johne R (2014) Detection and characterization of potentially zoonotic viruses in faeces of pigs at slaughter in Germany. Vet Microbiol 168:60-68. https://doi.org/10.1016/j.vetmic.2013.10.018

13. Monini M, Di Bartolo I, laniro G, Angeloni G, Magistrali CF, Ostanello F, Ruggeri FM (2015) Detection and molecular characterization of zoonotic viruses in swine fecal samples in Italian pig herds. Arch Virol 160:2547-2556. .https://doi.org/10.1007/s00705-015-2538-4

14. Dufkova L, Scigalkova I, Moutelikova R, Malenovska H, Prodelalova J (2013) Genetic diversity of porcine sapoviruses, kobuviruses, and astroviruses in asymptomatic pigs: an emerging new sapovirus GIII genotype. Arch Virol 158:549-558. https://doi.org/10.1007/s00705-012-1528-z

15. Mendenhall IH, Smith GJ, Vijaykrishna D (2015) Ecological drivers of virus evolution: Astrovirus as a case study. J Virol 89:6978-6981. https://doi.org/10.1128/JVI.02971-14

16. Czechowicz J, Huaman JL, Forshey BM, Morrison AC, Castillo R, Huaman A, Caceda R, Eza D, Rocha C, Blair PJ (2011) Prevalence and risk factors for encephalomyocarditis virus infection in Peru. 
Vector-Borne and Zoonotic Diseases 11:367-374. .https://doi.org/10.1089/vbz.2010.0029

17. Martella V, Lorusso E, Banyai K, Decaro N, Corrente M, Elia G, Cavalli A, Radogna A, Costantini V, Saif $L$ (2008) Identification of a porcine calicivirus related genetically to human sapoviruses. J Clin Microbiol 46:1907-1913. https://doi.org/10.1128/JCM.00341-08

18. Vlasova AN, Amimo JO, Saif LJ (2017) Porcine Rotaviruses: Epidemiology, Immune Responses and Control Strategies. Viruses 9. https://doi.org/10.3390/v9030048

19. Lipkin WI, Firth C (2013) Viral surveillance and discovery. Current opinion in virology 3:199-204. .https://doi.org/10.1016/j.coviro.2013.03.010

20. Akdag Al, Gupta S, Khan N, Upadhayay A, Ray P (2020) Epidemiology and clinical features of rotavirus, adenovirus, and astrovirus infections and coinfections in children with acute gastroenteritis prior to rotavirus vaccine introduction in Meerut, North India. J Med Virol 92:1102-1109. https://doi.org/10.1002/jmv.25645

21. Zhang Q, Hu R, Tang X, Wu C, He Q, Zhao Z, Chen H, Wu B (2013) Occurrence and investigation of enteric viral infections in pigs with diarrhea in China. Arch Virol 158:1631-1636. .https://doi.org/10.1007/s00705-013-1659-x

22. Valko A, Marosi A, Csagola A, Farkas R, Ronai Z, Dan A (2019) Frequency of diarrhoea-associated viruses in swine of various ages in Hungary. Acta Vet Hung 67:140-150. .https://doi.org/10.1556/004.2019.016

23. Zhao J, Shi BJ, Huang XG, Peng MY, Zhang XM, He DN, Pang R, Zhou B, Chen PY (2013) A multiplex RT-PCR assay for rapid and differential diagnosis of four porcine diarrhea associated viruses in field samples from pig farms in East China from 2010 to 2012. J Virol Methods 194:107-112. .https://doi.org/10.1016/j.jviromet.2013.08.008

24. Yue F, Cui S, Zhang C, Yoon KJ (2009) A multiplex PCR for rapid and simultaneous detection of porcine circovirus type 2 , porcine parvovirus, porcine pseudorabies virus, and porcine reproductive and respiratory syndrome virus in clinical specimens. Virus Genes 38:392-397. .https://doi.org/10.1007/s11262-009-0333-6

25. Ding G, Fu Y, Li B, Chen J, Wang J, Yin B, Sha W, Liu G (2020) Development of a multiplex RT-PCR for the detection of major diarrhoeal viruses in pig herds in China. Transbound Emerg Dis 67:678-685. .https://doi.org/10.1111/tbed.13385

26. Liu S, Zhao Y, Hu Q, Lv C, Zhang C, Zhao R, Hu F, Lin W, Cui S (2011) A multiplex RT-PCR for rapid and simultaneous detection of porcine teschovirus, classical swine fever virus, and porcine reproductive and respiratory syndrome virus in clinical specimens. J Virol Methods 172:88-92. https://doi.org/10.1016/j.jviromet.2010.12.023

27. Untergasser A, Cutcutache I, Koressaar T, Ye J, Faircloth BC, Remm M, Rozen SG (2012) Primer3new capabilities and interfaces. Nucleic Acids Res 40:e115. e115.https://doi.org/10.1093/nar/gks596

28. Saitou N, Nei M (1987) The neighbor-joining method: a new method for reconstructing phylogenetic trees. Mol Biol Evol 4:406-425. https://doi.org/10.1093/oxfordjournals.molbev.a040454 
29. Kumar S, Stecher G, Li M, Knyaz C, Tamura K (2018) MEGA X: molecular evolutionary genetics analysis across computing platforms. Mol Biol Evol 35:1547. https://doi.org/10.1093/molbev/msy096

30. Tamura K, Nei M, Kumar S (2004) Prospects for inferring very large phylogenies by using the neighbor-joining method. Proceedings of the National Academy of Sciences 101:1103011035.https://doi.org/10.1073/pnas.0404206101

31. Oka T, Lu Z, Phan T, Delwart EL, Saif LJ, Wang Q (2016) Genetic characterization and classification of human and animal sapoviruses. PLoS ONE 11:e0156373. https://doi.org/10.1371/journal.pone.0156373

32. Scheuer KA, Oka T, Hoet AE, Gebreyes WA, Molla BZ, Saif LJ, Wang Q (2013) Prevalence of porcine noroviruses, molecular characterization of emerging porcine sapoviruses from finisher swine in the United States, and unified classification scheme for sapoviruses. J Clin Microbiol 51:2344-2353. https://doi.org/10.1128/JCM.00865-13

33. Yinda CK, Conceição-Neto N, Zeller M, Heylen E, Maes P, Ghogomu SM, Van Ranst M, Matthijnssens J (2017) Novel highly divergent sapoviruses detected by metagenomics analysis in straw-colored fruit bats in Cameroon: Divergent bat sapoviruses. Emerging microbes \& infections 6:1-7. https://doi.org/10.1038/emi.2017.20

34. Wang L, Marthaler D, Fredrickson R, Gauger PC, Zhang J, Burrough ER, Petznick T, Li G (2020) Genetically divergent porcine sapovirus identified in pigs, United States. Transboundary and emerging diseases 67:18-28. https://doi.org/10.1111/tbed.13337

35. Carocci M, Bakkali-Kassimi L (2012) The encephalomyocarditis virus. Virulence 3:351-367. .https://doi.org/10.4161/viru.20573

36. Liu H, Li Y, Zhang G, Sang S, Wang C, Chang H (2017) Complete genome sequences and phylogenetic analysis of encephalomyocarditis virus strains isolated from pigs and rats origin. Infect Genet Evol 55:277-280. .https://doi.org/10.1016/j.meegid.2017.09.032

37. Templeton KE, Scheltinga SA, Graffelman AW, Van Schie JM, Crielaard JW, Sillekens P, Van Den Broek PJ, Goossens H, Beersma MF, Claas EC (2003) Comparison and evaluation of real-time PCR, real-time nucleic acid sequence-based amplification, conventional PCR, and serology for diagnosis of Mycoplasma pneumoniae. J Clin Microbiol 41:4366-4371. https://doi.org/10.1128/JCM.41.9.43664371.2003

38. Ogawa H, Taira O, Hirai T, Takeuchi H, Nagao A, Ishikawa Y, Tuchiya K, Nunoya T, Ueda S (2009) Multiplex PCR and multiplex RT-PCR for inclusive detection of major swine DNA and RNA viruses in pigs with multiple infections. J Virol Methods 160:210-214.

.https://doi.org/10.1016/j.jviromet.2009.05.010

39. Xu XG, Chen GD, Huang Y, Ding L, Li ZC, Chang CD, Wang CY, Tong DW, Liu HJ (2012) Development of multiplex PCR for simultaneous detection of six swine DNA and RNA viruses. J Virol Methods 183:69-74. .https://doi.org/10.1016/j.jviromet.2012.03.034 
40. Liu H, Shi K, Sun W, Zhao J, Yin Y, Si H, Qu S, Lu W (2021) Development a multiplex RT-PCR assay for simultaneous detection of African swine fever virus, classical swine fever virus and atypical porcine pestivirus. J Virol Methods 287:114006. https://doi.org/10.1016/j.jviromet.2020.114006

41. Hu L, Lin XY, Yang ZX, Yao XP, Li GL, Peng SZ, Wang Y (2015) A multiplex PCR for simultaneous detection of classical swine fever virus, African swine fever virus, highly pathogenic porcine reproductive and respiratory syndrome virus, porcine reproductive and respiratory syndrome virus and pseudorabies in swines. Pol J Vet Sci 18:715-723. https://doi.org/10.1515/pjvs-2015-0093

42. Nakhaie M, Soleimanjahi H, Mollaie HR, Arabzadeh SMA (2018) Development of multiplex reverse transcription-polymerase chain reaction for simultaneous detection of influenza $A, B$ and adenoviruses. Iranian journal of pathology 13:54. https://doi.org/10.1182/blood.V92.2.574

43. Kim O, Choi C, Kim B, Chae C (2000) Detection and differentiation of porcine epidemic diarrhoea virus and transmissible gastroenteritis virus in clinical samples by multiplex RT-PCR. Vet Rec 146:637640. .https://doi.org/10.1136/vr.146.22.637

44. Huang C, Hung JJ, Wu CY, Chien MS (2004) Multiplex PCR for rapid detection of pseudorabies virus, porcine parvovirus and porcine circoviruses. Vet Microbiol 101:209-214.

https://doi.org/10.1016/j.vetmic.2004.04.007

45. Day JM, Spackman E, Pantin-Jackwood M (2007) A multiplex RT-PCR test for the differential identification of turkey astrovirus type 1, turkey astrovirus type 2, chicken astrovirus, avian nephritis virus, and avian rotavirus. Avian Dis 51:681-684. https://doi.org/10.1637/00052086(2007)51[681:AMRTFT]2.0.C0;2

46. Cagirgan AA, Yazici Z (2020) Development of a multiplex RT-PCR assay for the routine detection of seven RNA viruses in Apis mellifera. J Virol Methods 281:113858.

https://doi.org/10.1016/j.jviromet.2020.113858

47. Zhao ZP, Yang Z, Lin WD, Wang WY, Yang J, Jin WJ, Qin AJ (2016) The rate of co-infection for piglet diarrhea viruses in China and the genetic characterization of porcine epidemic diarrhea virus and porcine kobuvirus. Acta Virol 60:55-61. https://doi.org/10.4149/av_2016_01_55

48. Chen Q, Wang L, Zheng Y, Zhang J, Guo B, Yoon K-J, Gauger PC, Harmon KM, Main RG, Li G (2018) Metagenomic analysis of the RNA fraction of the fecal virome indicates high diversity in pigs infected by porcine endemic diarrhea virus in the United States. Virol J 15:1-9. .https://doi.org/10.1186/s12985-018-1001-z

49. Theuns S, Vanmechelen B, Bernaert Q, Deboutte W, Vandenhole M, Beller L, Matthijnssens J, Maes P, Nauwynck HJ (2018) Nanopore sequencing as a revolutionary diagnostic tool for porcine viral enteric disease complexes identifies porcine kobuvirus as an important enteric virus. Sci Rep 8:1-13. https://doi.org/10.1038/s41598-018-28180-9

50. Li J, Shen Q, Zhang W, Zhao T, Li Y, Jiang J, Yu X, Guo Z, Cui L, Hua X (2017) Genomic organization and recombination analysis of a porcine sapovirus identified from a piglet with diarrhea in China. Virol J 14:57. https://doi.org/10.1186/s12985-017-0729-1 
51. Liu ZK, Li JY, Pan H (2014) Seroprevalence and molecular detection of porcine sapovirus in symptomatic suckling piglets in Guangdong Province, China. Trop Anim Health Prod 46:583-587. .https://doi.org/10.1007/s11250-013-0531-z

52. Chang H, Chen L, Zhao J, Wang X, Yang X, Yao H, Wang C (2014) Complete genome sequence of porcine encephalomyocarditis virus from an aardvark in china. Genome Announc 2. https://doi.org/10.1128/genomeA.00017-14

53. Yuan W, Song Q, Zhang X, Zhang L, Sun J (2014) Isolation and molecular analysis of porcine encephalomyocarditis virus strain BD2 from northern China. Infect Genet Evol 21:303-307. .https://doi.org/10.1016/j.meegid.2013.11.014

54. Matthijnssens J, Ciarlet M, McDonald SM, Attoui H, Bányai K, Brister JR, Buesa J, Esona MD, Estes MK, Gentsch JR (2011) Uniformity of rotavirus strain nomenclature proposed by the Rotavirus Classification Working Group (RCWG). Arch Virol 156:1397-1413. .https://doi.org/10.1007/s00705011-1006-z

55. Xiao C-T, Giménez-Lirola LG, Gerber PF, Jiang Y-H, Halbur PG, Opriessnig T (2013) Identification and characterization of novel porcine astroviruses (PAstVs) with high prevalence and frequent coinfection of individual pigs with multiple PAstV types. J Gen Virol 94:570-582. .https://doi.org/10.1099/vir.0.048744-0

56. Kumthip K, Khamrin P, Saikruang W, Kongkaew A, Vachirachewin R, Ushijima H, Maneekarn N (2018) Detection and genetic characterization of porcine astroviruses in piglets with and without diarrhea in Thailand. Arch Virol 163:1823-1829. .https://doi.org/10.1007/s00705-018-3806-x

57. Su M, Qi S, Yang D, Guo D, Yin B, Sun D (2020) Coinfection and Genetic Characterization of Porcine Astrovirus in Diarrheic Piglets in China From 2015 to 2018. Front Vet Sci 7:462. https://doi.org/10.3389/fvets.2020.00462

58. Xiao C-T, Luo Z, Lv S-L, Opriessnig T, Li R-C, Yu X-L (2017) Identification and characterization of multiple porcine astrovirus genotypes in Hunan province, China. Arch Virol 162:943-952. https://doi.org/10.1007/s00705-016-3185-0

59. Boniotti MB, Papetti A, Lavazza A, Alborali G, Sozzi E, Chiapponi C, Faccini S, Bonilauri P, Cordioli P, Marthaler D (2016) Porcine Epidemic Diarrhea Virus and Discovery of a Recombinant Swine Enteric Coronavirus, Italy. Emerg Infect Dis 22:83-87. https://doi.org/10.3201/eid2201.150544

60. Akimkin V, Beer M, Blome S, Hanke D, Höper D, Jenckel M, Pohlmann A (2016) New chimeric porcine coronavirus in swine feces. Germany 2012 Emerging infectious diseases 22:1314. https://doi.org/10.3201/eid2207.160179

\section{Figures}

\section{Figure 1}


mRT-PCR optimization and assay specificity. M:2000 bp marker, 1: SaV, 2: EMCV, 3: RVA and 4: AstV, P: standard plasmid template mix containing SaV, EMCV, RVA and AstV fragments. (A) Optimization of mRTPCR using plasmids containing SaV, EMCV, RVA and AstV fragments. (B) Assay specificity. N: negative control, 1: SaV, 2: EMCV, 3: RVA, 4: AstV and 5-10: cDNA of PEDV, SVV, TGEV, PRRSV, PDCoV and PSV respectively

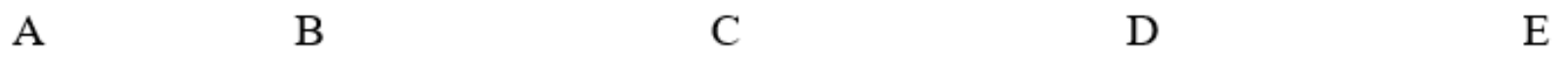

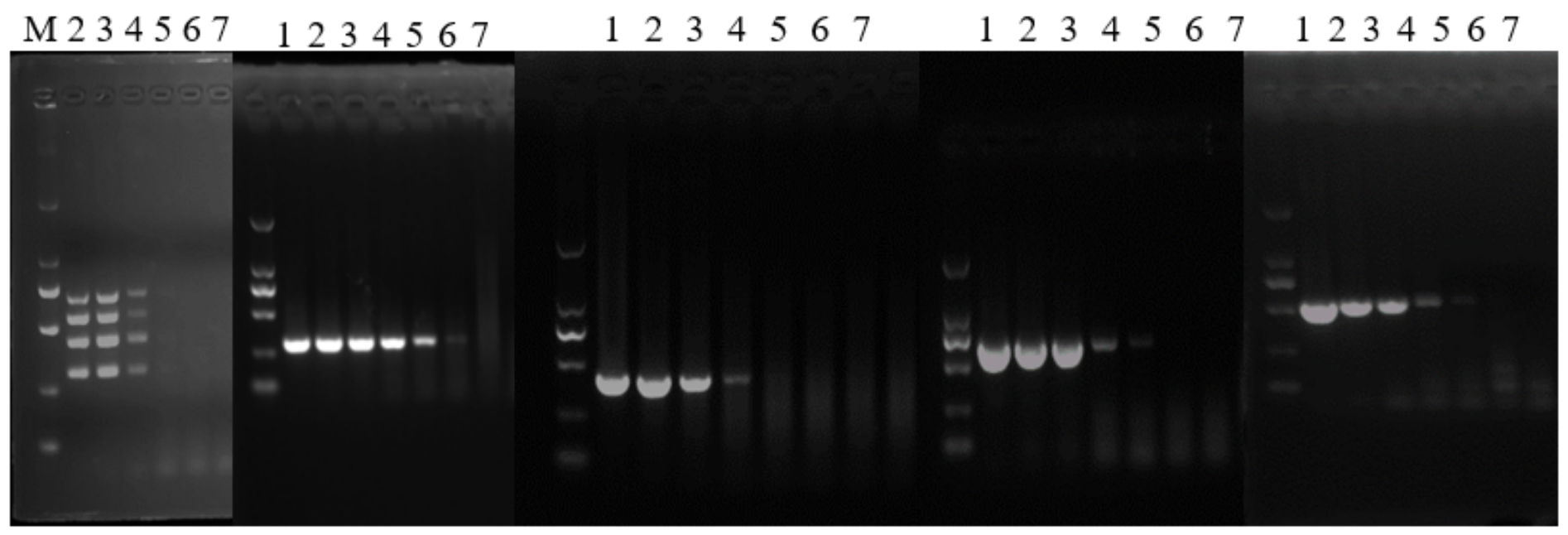

Figure 2

mRT-PCR assay sensitivity. The sensitivity of mRT-PCR and SRT-PCR assays was checked using 10 -fold serially diluted plasmids containing SaV, EMCV, RVA and AstV fragments as a template. M: DL2000 DNA Marker, $1: 2.5 \times 10^{6}$ copies, $2: 2.5 \times 10^{5}$ copies, $3: 2.5 \times 10^{4}$ copies $4: 2.5 \times 10^{3}$ copies, $5: 2.5 \times 10^{2}$ copies, 6 : $2.5 \times 10^{1}$ copies and $7: 2.5 \times 10^{0}$ copies. (A) mRT-PCR, (B) SaV, (C) EMCV, (D) RVA, and (E) AstV.

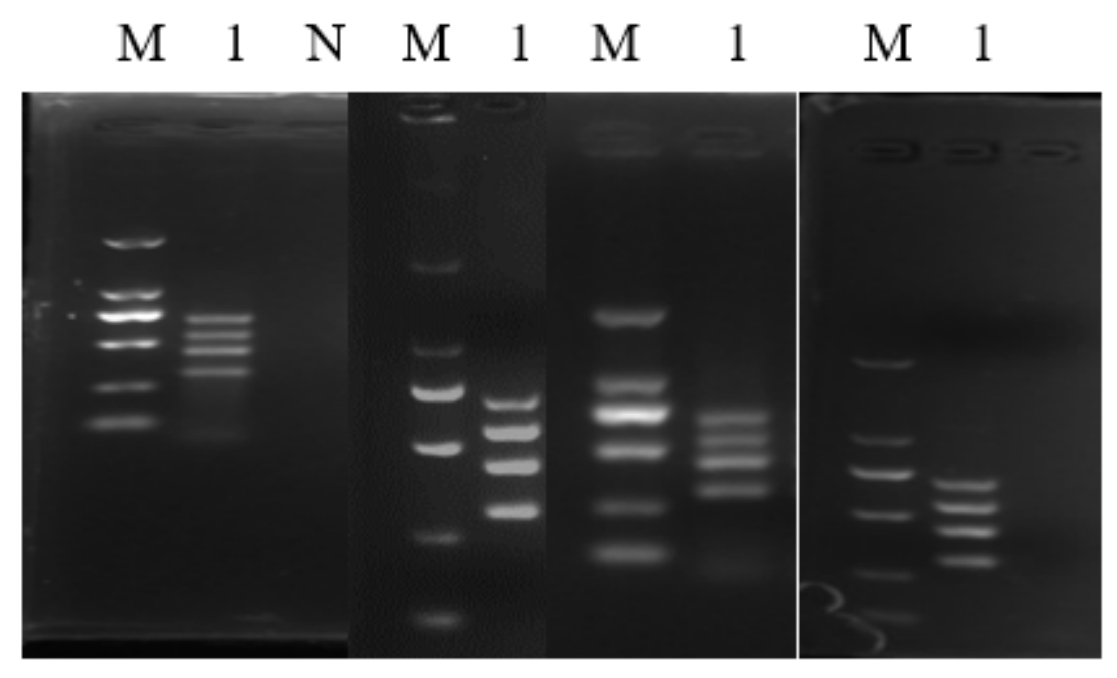

Figure 3 
Assay reproducibility. M:2000 bp marker, 1: standard template plasmid mix containing SaV, EMCV, RVA and AstV fragments, $\mathrm{N}$ : negative control
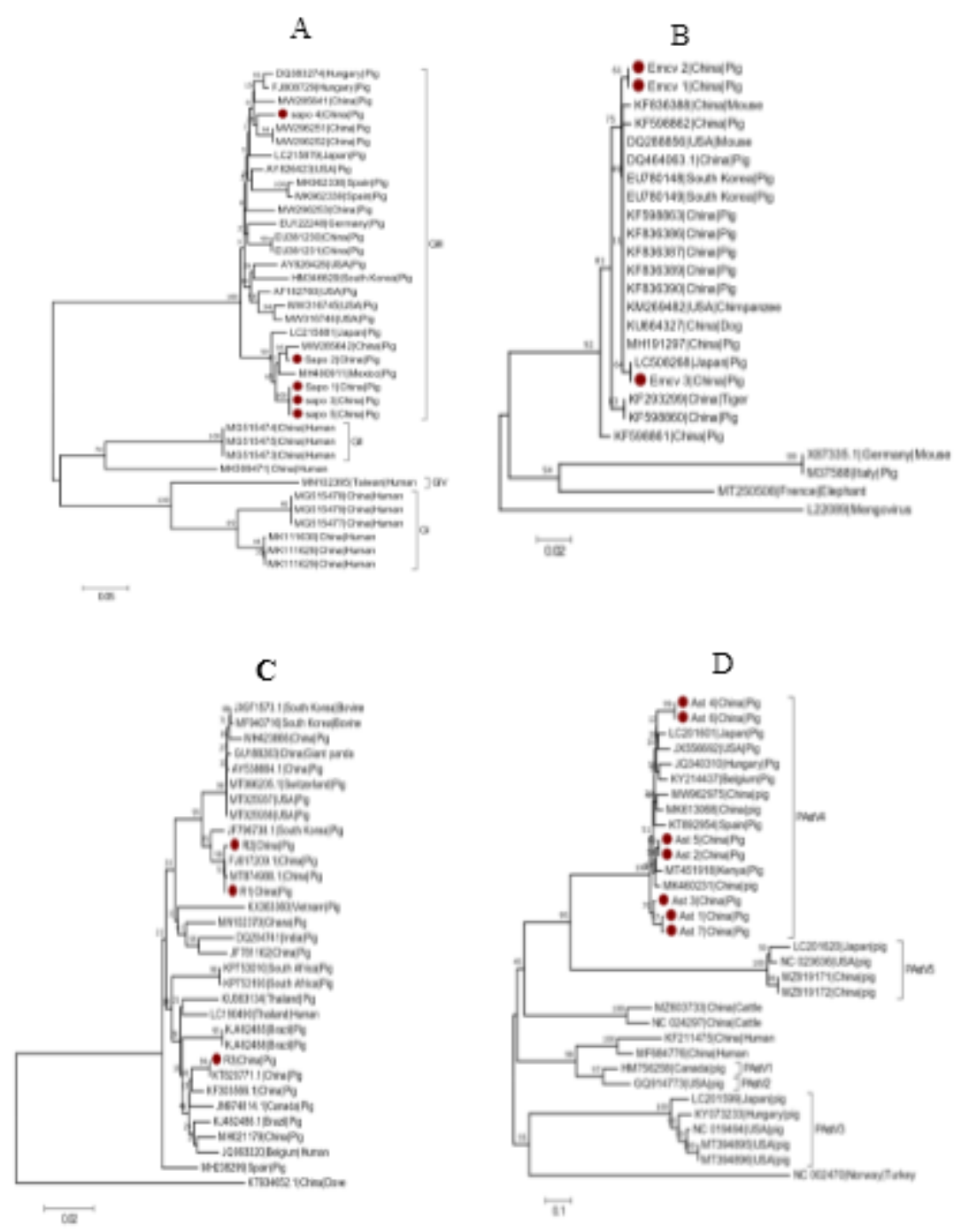

Figure 4

Phylogenetic analysis of SaV, EMCV, RVA and AstV. Scales indicate units of the number of base substitutions per site and variants detected in this study are marked with red circles (O). (A) Phylogenetic tree of SaV. The tree was built using 37 sequences and 224 positions from the ORF1 region of SaV. (B) Phylogenetic tree of EMCV. The tree was constructed using 25 nucleotide sequences and 211 positions from the 3D region of the EMCV. Mengovirus is used as an outgroup. (C) Phylogenetic tree of RVA. The tree was built based on 545 positions from the RVA's VP6 region and a total of 32 nucleotide sequences. Rotavirus A from dove (avian) is used as an outgroup. (D) Phylogenetic tree of AstV. The tree was built based on 379 positions from the AstV ORF1ab region and a total of 32 nucleotide sequences. As an outgroup, Turkey (avian) is included. 


\section{Supplementary Files}

This is a list of supplementary files associated with this preprint. Click to download.

- AstV.fasta

- EMCV.fasta

- RVA.fasta

- SaV.fasta 